\title{
Intravenous streptokinase treatment and serum C-reactive protein in patients with acute myocardial infarction
}

\author{
KARI PIETILÄ, * AIMO HARMOINEN, $\ddagger$ LAURI PÖYHÖNEN, $\dagger$ \\ MATTI KOSKINEN, $\dagger$ JUHANI HEIKKILÄ,§ REINO RUOSTEENOJA * \\ From the Departments of ${ }^{\star}$ Medicine and $\dagger$ Clinical Physiology, and $\ddagger$ Clinical Chemistry Unit, Tampere \\ University Central Hospital and Institute of Clinical Sciences, University of Tampere, and the §First \\ Department of Medicine, University of Helsinki, Finland
}

SUMMARY Serum concentrations of C-reactive protein were studied in 23 patients with acute myocardial infarction. In 14 patients who did not receive thrombolytic treatment there was a linear relation between infarct size (determined by serial creatine kinase-MB determinations and thallium-201 isotope emission tomography) and the $\mathrm{C}$-reactive protein response. The correlation coefficient between the concentration-time integrals of creatine kinase-MB and C-reactive protein was $\mathbf{0 . 9 6}$. The correlation coefficient between the creatine kinase-MB concentration-time integral and the peak serum value of C-reactive protein was 0.93 . In the nine patients who received intravenous streptokinase treatment there was also a positive correlation between the concentration-time integrals of creatine kinase-MB and C-reactive protein. The relation, however, depended on the success of the treatment. In patients with successful reperfusion the C-reactive protein response was only approximately $20 \%$ of that in patients in whom reperfusion failed or who received no thrombolytic treatment and who were matched by infarct size. When thrombolysis was successful the correlation coefficient between the concentration-time integrals of creatine kinase-MB and C-reactive protein was $0 \cdot 86$.

Daily measurement of serum C-reactive protein is useful in evaluating infarct size in patients with acute myocardial infarction who do not receive thrombolytic treatment. In patients treated with streptokinase C-reactive protein concentrations may be used to assess the success of thrombolysis.

Infarct size is the most important single factor influencing prognosis after acute myocardial infarction, ${ }^{12}$ but its determination by clinical chemical means is difficult. Total releases of creatine kinase or its $\mathrm{MB}$ isoenzyme correlate well with the size of myocardial infarction ${ }^{3-5}$ but are difficult to measure in routine clinical work. C-reactive protein is synthesised in the liver and its synthesis is stimulated by a number of diseases, including acute myocardial infarction. ${ }^{6}$ It has been shown that the rise in Creactive protein during infarction correlates with the

Requests for reprints to Dr Kari Pietilä, Department of Medicine, Institute of Clinical Sciences, Tampere University, PO Box 607, SF-33101 Tampere, Finland.

Accepted for publication 11 May 1987 activity of serum creatine kinase-MB, ${ }^{7}$ but the correlation of C-reactive protein with infarct size has as yet been little studied. We found that serum Creactive protein may not rise in certain non- $Q$ wave infarcts. ${ }^{8}$ Most non-Q wave infarcts result from an acute temporary imbalance between myocardial oxygen supply and demand with rapid restoration of adequate perfusion. ${ }^{9}$ Rapid perfusion of an infarcted myocardium could diminish the stimulus for Creactive protein synthesis in the liver by altering the development of the infarction. If this is the case, successful thrombolytic treatment of an acute myocardial infarct should have a similar effect.

We studied serum concentrations of $\mathrm{C}$-reactive protein in both streptokinase and non-streptokinase treated patients with acute myocardial infarction. 


\section{Patients and methods}

We studied 23 patients (mean (SD) age $56(10)$ years) with a first acute myocardial infarction. The patients were selected for the study according to the following criteria: acute chest pain and arrival at the hospital within four hours of onset of pain, diagnostic ST segment elevations in the first electrocardiogram that did not disappear after treatment with glyceryl trinitrate, and subsequent development into diagnostic $Q$ waves.

Nine patients (mean (SD) age $53(7)$ ) received high dose (1.8 million units) intravenous streptokinase given over an hour. In seven of the nine streptokinase treated patients reperfusion was considered successful as judged by indirect criteria of reperfusion: early peaking of total serum creatine kinase and creatine kinase-MB values $(13(2) \mathrm{h}$ and $11(2) \mathrm{h}$ respectively), relief of chest pain, and improvement in electrocardiographic ST shifts. Six patients had arrhythmias typical of reperfusion. In two patients reperfusion was considered to have failed because of late peak values of creatine kinase (24 and $28 \mathrm{~h}$ ) and creatine kinase-MB (20 and $24 \mathrm{~h}$ ) and continuing chest pain after streptokinase infusion. Although indirect means were used to evaluate the success of reperfusion, coronary angiography was undertaken in all patients two to four weeks later. In the two patients in whom reperfusion was not considered to have taken place there was occlusion of the infarct related coronary artery, whereas in the others a variable degree of coronary atherosclerosis was noted but without occlusion of any of the coronary arteries. Because streptokinase treatment was not started in our hospital until after the start of the present study only nine patients were given streptokinase.

Blood samples were taken immediately on arrival and 2 (when feasible), 4, 6, 8, 12, 24, 32, and 48 hours after the onset of chest pain and then daily until discharge or for two weeks. The samples were analysed for total creatine kinase and creatine kinaseMB activities (reference values $0-250 \mathrm{U} / 1$ and $0-25 \mathrm{U} / \mathrm{l}$, respectively) as well as $\mathrm{C}$-reactive protein concentrations $(0-10 \mathrm{mg} / 1)$. The activity of creatine kinase was determined at $37^{\circ} \mathrm{C}$ according to the recommendations of the Scandinavian Committee on Enzymes. ${ }^{1011}$ The creatine kinase-M moiety was inhibited with $M$-specific antibodies ${ }^{12}$ and the remaining creatine kinase activity (creatine kinase$\mathrm{MB}$ moiety) was determined at $37^{\circ} \mathrm{C}$ with the same reagents (from Boehringer Mannheim, Federal Republic of Germany) as in the assay of total creatine kinase. Total creatine kinase, creatine kinase-B, and C-reactive protein ${ }^{13}$ were measured with a Hitachi 705 analyser (Oriola Oy, Espoo, Finland).
Thallium-201 isotope emission tomography with a rotating gamma camera (GE 400T Maxicamera, tomography software from Nuclear Diagnostics, Sweden) was carried out at rest during the second week after the onset of pain. The volume of infarction was calculated by a semiautomatic computer program from a set of short axis pictures. In this method an absolute scaling from a slice (with a thickness of $13 \mathrm{~mm}$ ) was first carried out. Then the estimated inner and outer contours of the left ventricle and the contour of the intact myocardium were delineated. The difference between these areas was taken to represent the scar tissue in this particular slice of heart. The total volume of the infarct in millilitres was then estimated by summing the results from all slices.

We used regression analysis and calculation of the correlation coefficient for statistical analysis.

\section{Results}

In all patients (both those treated conventionally and those treated with streptokinase) there was a good correlation between the areas under the creatine kinase-MB curves (concentration-time integral) and the results of thallium-201 isotope emission tomography $(r=0.72 ; p<0.001 ;$ fig 1$)$ and the relation

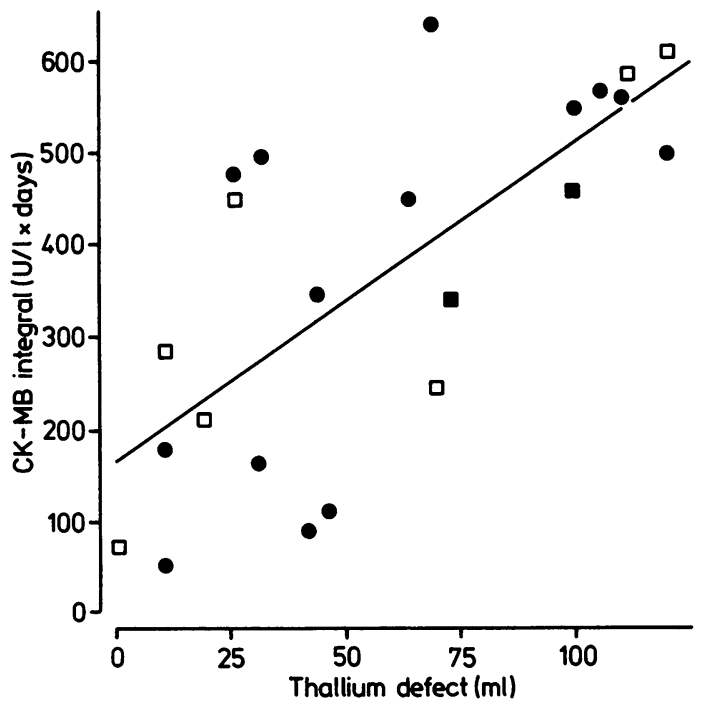

Fig 1 Relation between creatine kinase-MB (CK-MB) concentration-time integral $(U / l \times$ days) and defect $(m l)$ estimated by thallium-201 isotope emission tomography. O, conventionally treated patients; $\square$, streptokinase treated patients with reperfusion; $\square$, streptokinase treated patients without reperfusion. The correlation coefficient of the data from all patients is $0.72(p<0.001)$ and the equation of the regression line is $y=3.6 x+160$ $(p<0.001)$. 


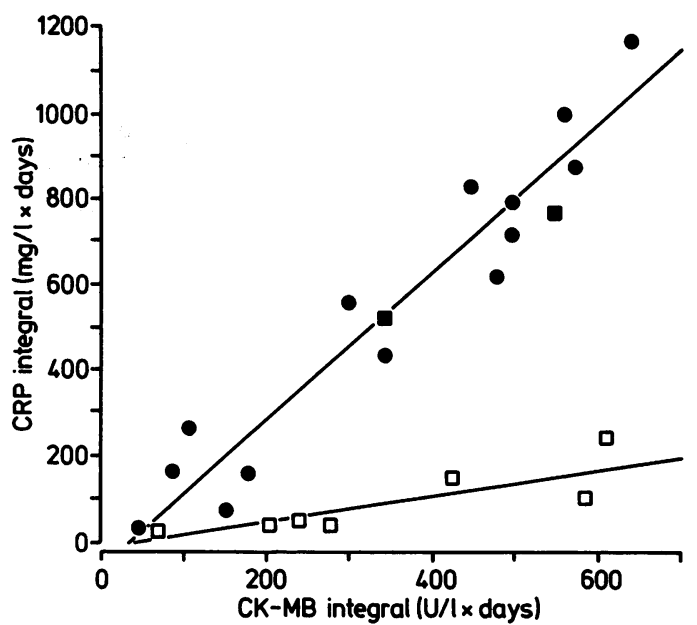

Fig 2 Relation between C-reactive protein (CRP) concentration-time integral $(\mathrm{mg} / \mathrm{l} \times$ days) and creatine kinase- $M B(C K-M B)$ concentration time integral $(U / l \times$ days)., conventionally treated patients; $\square$, streptokinase treated patients with reperfusion; $\square$, streptokinase treated patients without reperfusion. The correlation coefficient for the data from the conventionally treated patients was 0.96 $(p<0.001)$ and the equation of the regression line (the upper line in the figure) is $y=1.8 x-72(p<0.001)$. The correlation coefficient for the data from the patients with a successful streptokinase treatment is 0.86 $(p<0.05)$ and the equation of the regression line (the lower line in the figure) is $y=0.4 x-40(p<0.05)$.

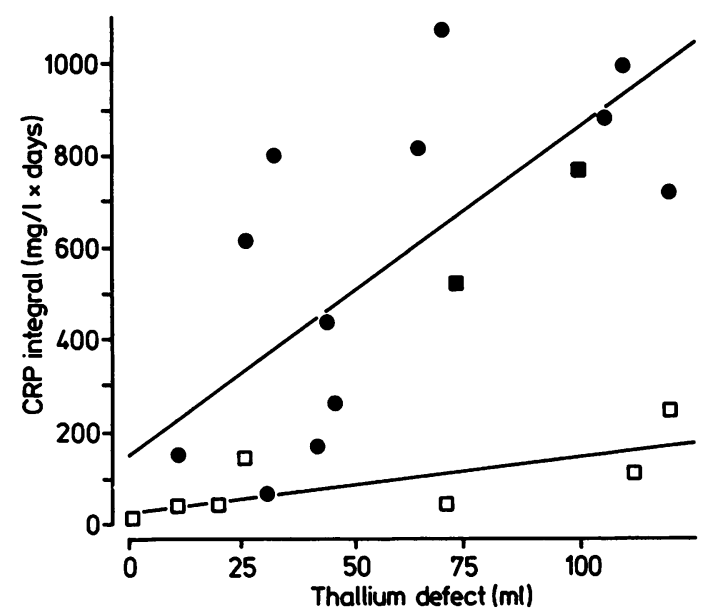

Fig 3 Relation between C-reactive protein (CRP) concentration-time integral $(\mathrm{mg} / \mathrm{l} \times$ days) and defect $(\mathrm{ml})$ estimated by thallium-201 isotope emission tomography. O, conventionally treated patients; $\square$, streptokinase treated patients with reperfusion; , streptokinase treated patients without reperfusion. The correlation coefficient for the data from conventionally treated patients is 0.69 $(p<0.01)$ and the equation of the regression line (the upper line in the figure) is $y=7.2 \times 156(p<0.01)$. The correlation coefficient for the dat a from the patients with a successful streptokinase treatment is 0.67 (NS) and the equation of the regression line is $y=1.2 x+32$ (NS). did not depend on the success of streptokinase treatment.

In those patients who were not given streptokinase treatment the peak serum values of creatine kinase$\mathrm{MB}$ and $\mathrm{C}$-reactive protein correlated positively with each other $(r=0.89 ; p<0.001)$. The correlation was improved if concentration-time integrals were used instead of peak serum concentrations $(r=0.96 ; p<0.001$, fig 2$)$. The peak value of serum C-reactive protein correlated with the concentration-time integral of creatine kinase-MB at least as
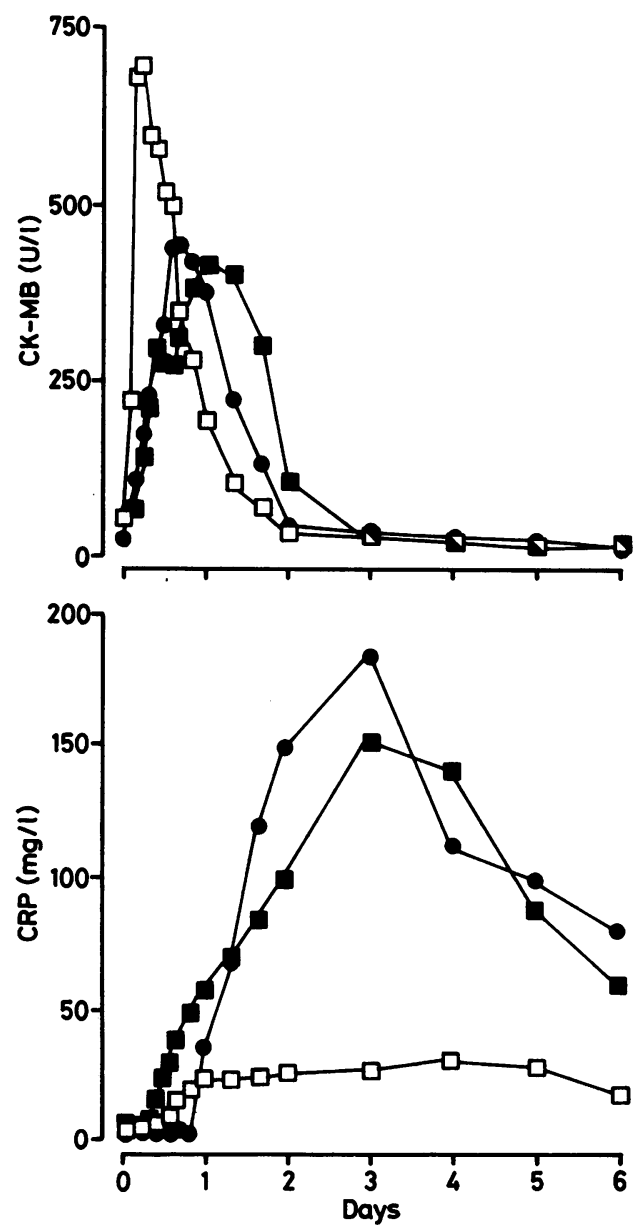

Fig 4 Change in concentrations of serum $C$-reactive protein $(C R P)$ and creatine kinase-MB $(C K-M B)$ with time after the onset of chest pain in three patients with an anterior wall myocardial infarction. $\bigcirc$, a conventionally treated patient; $\square$, a streptokinase treated patient with reperfusion; $\square$, a streptokinase treated patient without reperfusion. The volumes ( $\mathrm{ml}$ ) of defects estimated by thallium-201 isotope emission tomography were 106, 112, and 119 and the concentration-time integrals of creatine kinase $-M B(U / l \times$ days $)$ were 571, 585, and 549 respectively. 
well as the peak value of serum creatine kinase-MB itself did ( $r=0.93$ and 0.91 , respectively). The correlation between the peak $\mathrm{C}$-reactive protein value and C-reactive protein concentration-time integral was 0.96 . There was also a positive correlation between the thallium-201 isotope emission tomography results and the $\mathrm{C}$-reactive protein response ( $r=0.69 ; p<0.01$; fig 3$)$.

If the patients were treated with intravenous streptokinase and reperfusion was achieved the C-reactive protein response was less than $20 \%$ of that in patients who did not receive thrombolytic treatment and were matched by infarct size according to creatine kinase-MB concentration-time integral and thallium-201 isotope emission tomography defect (figs 2 and 3). There was still a positive correlation between infarct size and the $\mathrm{C}$-reactive protein response. If reperfusion was not achieved the response of C-reactive protein was similar to that in patients not treated with streptokinase (figs 2 and 3 ).

Figure 4 shows the $\mathrm{C}$-reactive protein and creatine kinase-MB curves of three patients with an anterior wall myocardial infarction matched by infarct size according to thallium-201 emission tomography defect and creatine kinase-MB concentration-time integral. This shows that the C-reactive protein responses of the patients in whom there was no reperfusion were similar, whereas the patient with successful reperfusion showed hardly any C-reactive protein response despite his large infarct. The patient with successful reperfusion felt considerably better than the other two in the first three days after infarction. Indeed, successful thrombolytic treatment tended to be associated with clinical wellbeing even if infarct size was not reduced. This sense of wellbeing seemed to correlate with the reduction in the rise in serum $\mathrm{C}$-reactive protein concentration that was associated with the acute phase of infarction.

\section{Discussion}

The present study assessed the value of serum Creactive protein as an estimate of infarct size. Like De Beer $e^{~} \mathrm{al}^{7}$ we found a good correlation between the peak serum concentrations of creatine kinase$\mathrm{MB}$ and C-reactive protein in patients not receiving thrombolytic treatment. The correlation was improved and the scatter was reduced if concentration-time integrals were used instead of peak values. Previous studies have shown that the concentration-time integral of creatine kinase-MB is a reliable estimate of infarct size. ${ }^{3-5} \mathrm{We}$ too found that the concentration-time integral of C-reactive protein correlated well with the results of thallium201 isotope emission tomography.
It is not convenient to calculate concentrationtime integrals in routine clinical work or to sample blood often enough to determine reliably the peak serum concentration of creatine kinase-MB, which is usually reached 8-30 h after the onset of an acute myocardial infarct. ${ }^{14}$ Serum C-reactive protein rises more slowly in the course of acute myocardial infarction ${ }^{8}$ and according to our present and previous results ${ }^{8}$ routine daily blood sampling seems to permit reliable detection of its peak serum concentrations. The good correlation between the peak serum value of $\mathrm{C}$-reactive protein and its concentration-time integral means that peak values are a useful way of estimating infarct size by laboratory means. Conditions other than myocardial infarction raise the concentration of serum Creactive protein ${ }^{6}$ and these may occasionally interfere with the determination of infarct size. This was not a problem in our patients. Although some non- $Q$ wave infarcts are not associated with a rise in Creactive protein, we do not think that this will lessen the value of the determination of $\mathrm{C}$-reactive protein in acute myocardial infarction.

In patients treated with intravenous streptokinase the rise in serum C-reactive protein depended on the success of thrombolysis as well as the infarct size. When reperfusion was successful there was only a modest rise in serum C-reactive protein even if the resultant myocardial infarction was large as judged by creatine kinase-MB concentration-time integral and the defect displayed by thallium-201 isotope emission tomography. With the possible exception of the smallest myocardial infarcts the measurement of serum C-reactive protein seems to permit the success of reperfusion after intravenous streptokinase treatment to be evaluated.

The reason for the modest response of C-reactive protein after successful thrombolytic treatment is not at present clear. When thrombolysis was not successful, the behaviour of serum C-reactive protein was similar to that in patients who had not received streptokinase treatment. This makes it unlikely that streptokinase itself or fibrinogen degradation products influenced the synthesis of $\mathrm{C}$-reactive protein in the liver. Serum C-reactive protein does not rise in certain non- $Q$ wave infarcts with features of subendocardial infarcts. ${ }^{8}$ It has been postulated that an adequate coronary blood flow is often rapidly restored in subendocardial infarcts ${ }^{9}$ : a situation resembling a successful reperfusion with streptokinase. It may be that a rapid reperfusion of the infarcted myocardium changes the evolution of infarction in such a way that the usual acute phase reaction does not take place. This may have clinical implications, and, indeed, the patients with reperfusion by intravenous streptokinase fared much 
better clinically than those with no reperfusion or thrombolytic treatment. This was true even if the patients were matched by infarct size as determined by the creatine kinase-MB concentration-time integral and the defect measured by thallium-201 isotope emission tomography. A more detailed study of the effect on the acute phase reaction on the clinical outcome seems warranted.

This study was supported by a grant from the Scientific Foundation of the City of Tampere.

\section{References}

1 Mock MB, Ringqvist I, Fiscger LD et al. Survival of medically treated patients in the coronary artery surgery study (CASS) registry. Circulation 1982;66:562-8.

2 Kelly MJ, Thompson PL, Quinlan MF. Prognostic significance of the left ventricular ejection fraction after acute myocardial infarction. A bedside radionuclide study. Br Heart $J$ 1985;53:16-24.

3 Rogers WJ, McDaniel HG, Smith LR, et al. Correlation of angiographic estimates of myocardial infarct size and accumulated release creatinine kinase isoenzyme in man. Circulation 1977;56:199-205.

4 Henning H, Schelberg HR, Righetti A, et al. Dual myocardial imaging with technetium-99m pyrophosphate and thallium-201 for detecting, localising and sizing acute myocardial infarction. Am J Cardiol 1977;147:147-55.

5 Grande P, Hansen BF, Christiansen C, Waestoff J.
Estimation of acute myocardial infarct size by serum CK-MB measurements. Circulation 1982;65:756-64.

6 Pepys MB. C-reactive protein fifty years on. Lancet $1981 ; \mathbf{i}: 653-7$.

7 de Beer FC, Hind CRK, Fox KM, Allan RM, Maseri A, Pepys MB. Measurement of serum C-reactive protein in myocardial ischaemia and infarction. $\mathrm{Br}$ Heart $J$ 1982;47:239-43.

8 Pietilä K, Harmoinen A, Pöyhönen L, Ruosteenoja R. C-reactive protein in subendocardial and transmural myocardial infarcts. Clin Chem 1986;8:1596-7.

9 Laeffel GL, Braunwald E. Thrombolytic therapy. A new strategy for the treatment of acute myocardial infarction (first of the two parts). N Engl J Med 1984; 311:710-7.

10 The Committee on Enzymes of the Scandinavian Society for Clinical Chemistry and Clinical Physiology. Recommended method for the determination of creatinine kinase in blood. Scand J Clin Lab Invest 1976;36:711-23.

11 The Committee on Enzymes of the Scandinavian Society for Clinical Chemistry and Clinical Physiology. Experiences with the Scandinavian recommended methods for the determination of enzymes in blood. Scand J Clin Lab Invest 1981;41:107-16.

12 Würzburg U, Hennrich $\mathrm{N}$, Lang $\mathrm{H}$, et al. Bestimmung der Aktivität von Creatinkinase MB in Serum unter Verwendung inhibierender Antikröper. Klin Wochenschr 1976;54:357-60.

13 Harmoinen A. Immunoassay of $\mathrm{C}$-reactive protein using the Hitachi 705E analyzer. J Clin Chem Clin Biochem 1985;23:45-6.

14 Ong L, Reiser P, Coromilas J, et al. Left ventricular function and rapid release of creatine kinase $\mathrm{MB}$ in acute myocardial infarction: evidence for spontaneous reperfusion. N Engl J Med 1983;309:1-6. 